\title{
Response to letter to the editor concerning "Orthopaedic surgery patients who use recreational marijuana have less pre-operative pain"
}

\author{
Vidushan Nadarajah ${ }^{1,2} \cdot$ Julio J. Jauregui ${ }^{1}$ (D. R. Frank Henn III ${ }^{1,3}$
}

Received: 5 May 2019 / Accepted: 9 May 2019 /Published online: 22 May 2019

(C) SICOT aisbl 2019

Dear Editor,

We appreciate the comments by Dr. Mai [1] regarding our article titled Orthopaedic Surgery Patients Who Use Recreational Marijuana Have Less Pre-Operative Pain [2]. Indeed, we are currently working on a follow-up study that should help answer many of these very important questions. Our current study was an analytical cross-sectional analysis of pre-operative patient-reported data, so we did not evaluate post-operative pain or any other post-operative data. Similarly, the use of intra-operative or post-operative nerve blocks was outside the scope of our study design. We did adjust for the type of surgery by including the operative joint and primary procedure in the multivariable regression analysis. Lastly, we analysed both pre-operative opioid use and marijuana use as binary categorical variables: "YES-opioiduse" or "NO-opioid-use", and "YES-non prescriptions drug use - marijuana" or "NO-prescription drug use - marijuana". We have found that pre-operative opioid use is an important factor in this patient population [3], and we controlled for this in our multivariable analysis. Accurate quantification of preoperative opioid use is very difficult in orthopaedic patients as many prescriptions are provided prior to evaluation by the orthopaedic surgeon. However, we agree that the amount of opioid use and the amount of marijuana use may be important and related.

Given the current trends of increased marijuana use (medically prescribed or recreational), the relationships identified

R. Frank Henn, III

Frank_Henn@yahoo.com

1 Department of Orthopaedics, University of Maryland School of Medicine, Baltimore, MD, USA

2 Department of Orthopaedic Surgery and Rehabilitation, SUNY Downstate College of Medicine, Brooklyn, NY, USA

3 University of Maryland Rehabilitation and Orthopaedic Institute, 2200 Kernan Drive, Baltimore, MD 21207, USA in our study are very relevant to not only orthopaedic practice, but also the medical community at large. We thank Dr. Mai again for the comments and look forward to further investigation regarding the factors associated with pain modulation in the peri-operative setting.

\section{Compliance with ethical standards}

Conflict of interest Dr. Henn reports research support from Arthrex, Inc., outside the submitted work.

All other named authors declare that they have no conflict of interest.

\section{References}

1. Mai H (2019) Comment on Medina et al.: orthopaedic surgery patients who use recreational marijuana have less pre-operative pain. Int Orthop. https://doi.org/10.1007/s00264-019-04319-9

2. Medina SH, Nadarajah V, Jauregui JJ, Smuda MP, Foster M, Meredith SJ, Packer JD, Henn RF 3rd (2019) Orthopaedic surgery patients who use recreational marijuana have less pre-operative pain. Int Orthop 43(2):283-292. https://doi.org/10.1007/s00264-0184101-x

3. Meredith SJ, Nadarajah V, Jauregui JJ, Smuda MP, Medina SH, Bennett CH, Packer JD, Henn RF 3rd (2018) Preoperative opioid use in knee surgery patients. J Knee Surg. https://doi.org/10.1055/s0038-1666868

Publisher's note Springer Nature remains neutral with regard to jurisdictional claims in published maps and institutional affiliations. 